\title{
Antioxidative probiotic fermented goats' milk decreases oxidative stress-mediated atherogenicity in human subjects
}

\author{
Tiiu Kullisaar ${ }^{1 \star}$, Epp Songisepp ${ }^{2}$, Marika Mikelsaar ${ }^{2}$, Kersti Zilmer $^{1}$, Tiiu Vihalemm ${ }^{1}$ and \\ Minkel Zilmer ${ }^{1}$ \\ ${ }^{1}$ Department of Biochemistry and ${ }^{2}$ Department of Microbiology, Medical Faculty, University of Tartu, Tartu, Estonia
}

(Received 23 May 2002 - Revised 11 February 2003 - Accepted 24 March 2003)

\begin{abstract}
The increasing interest in a healthy diet is stimulating innovative development of novel scientific products in the food industry. The viable lactic acid bacteria in fermented milk products, such as yoghurt, have been associated with increased lactose tolerance, a well-balanced intestinal microflora, antimicrobial activity, stimulation of the immune system and antitumoural, anticholesterolaemic and antioxidative properties in human subjects. Recently, we have studied a human Lactobacillus spp. strain that possesses antioxidative activity. The aim of the present pilot study was to develop goats' milk fermented with the human antioxidative lactobacilli strain, Lactobacillus fermentum ME-3, and to test the effect of the fermented probiotic goats' milk on oxidative stress markers (including markers for atherosclerosis) in human blood and urine and on the gut microflora. Twenty-one healthy subjects were assigned to two treatment groups: goats' milk group and fermented goats' milk group $(150 \mathrm{~g} / \mathrm{d})$ for a period of $21 \mathrm{~d}$. Consumption of fermented goats' milk improved anti-atherogenicity in healthy subjects: it prolonged resistance of the lipoprotein fraction to oxidation, lowered levels of peroxidized lipoproteins, oxidized LDL, 8-isoprostanes and glutathione redox ratio, and enhanced total antioxidative activity. The consumption of fermented goats' milk also altered both the prevalence and proportion of lactic acid bacteria species in the gut microflora of the subjects. We conclude that the goats' milk fermented with our special antioxidative lactobacilli strain Lactobacillus fermentum ME-3 exhibits anti-atherogenic effects.
\end{abstract}

Fermented goats' milk: Antioxidative activity: Oxidized LDL: Glutathione redox ratio: Atherosclerosis

Human microflora that inhabit the gastrointestinal tract (GIT) are part of an extremely complex and well-balanced ecosystem, where GIT micro-organisms interact not only with each other, but also with their host cells (Falk et al. 1998). Recently it has been shown that the regulation of GIT-associated lymphoid tissue may occur by action of probiotics, so it is possible that lactic acid bacteria (LAB) as beneficial organisms interact positively with the intestinal cells of the host (Isolauri et al. 2000; Kailasapathy \& Chin, 2000). Viable LAB (probiotics) of human origin help to restore normal intestinal microbial functions, alleviating disease symptoms in patients with GIT infection, stimulating the immune system, expressing anti-cancerogenic and anti-atherogenic effects (de Roos \& Katan, 2000; Lin \& Chang, 2000; McFarland, 2000; Isolauri, 2001).

The antioxidative effect of LAB has been reported only recently (Kaizu et al. 1993; Lin \& Yen, 1999; Lin \& Chang, 2000; Kullisaar et al. 2002). At the same time it has been established that a wide variety of reactive oxygen species are continuously produced in the human body and in food (De Zwart et al. 1999; Demple et al.
1999). Damage caused by reactive oxygen species plays a substantial role in the pathogenesis of cancer, cardiovascular diseases, allergies and atherosclerosis (AgerholmLarsen et al. 2000).

In a previous study, we have reported that a Lactobacillus fermentum strain, deposited in the Deutsche Sammlung von Mikroorganismen und Zellkulturen (DSMZ 14241, assigned as ME-3), possessed substantial antimicrobial and antioxidative activity, expressed manganese superoxide dismutase, eliminated hydroxyl radicals and contained reduced glutathione, a potent cellular antioxidant (Kullisaar et al. 2002). The antioxidative activity expressed by some Lactobacillus strains used as food components and probiotics may have a substantial impact on human welfare (Lin \& Chang, 2000; Oxman et al. 2000). To assess such possibilities, we have developed probiotic fermented goats' milk (GM), based on fresh GM and fermented with a human antioxidative strain L. fermentum ME-3. The aim of our present study was to test the effect of the probiotic fermented GM on oxidative stress markers (including markers for atherosclerosis) of human blood and urine and on the lactic acid microflora of the gut.

\footnotetext{
Abbreviations: CFU, colony-forming units; EPI, epi-prostaglandin $\mathrm{F}_{2 \alpha}$; GIT, gastrointestinal tract; GM, goats' milk; LAB, lactic acid bacteria; LPF, lipoprotein fraction; TAA, total antioxidant activity; TAS, total antioxidant status.

* Corresponding author: Dr Tiiu Kullisaar, fax +372 7 374312, email tiiukul@ut.ee
} 


\section{Materials and methods}

\section{Subjects}

The healthy volunteers were chosen according to selfassessment as healthy and some of them had taken part in earlier trials. The study participants were five men and sixteen women, mean age 50 (range 35-65) years. Inclusion and exclusion criteria in the pilot study were: age $>35$ years, no drugs of any kind, no vitamin supplementations, no other yoghurts, no special diet. Twentyone subjects took part in this trial: during the 3-week study, participants came every day to the Department of Microbiology, University of Tartu, where sixteen subjects consumed $150 \mathrm{~g}$ GM fermented with the antioxidative lactobacilli strains/d (study group) and five subjects consumed $150 \mathrm{~g}$ fresh GM/d (control group). Thus, the dose of probiotic lactobacilli for a subject was $3 \times 10^{11}$ colony forming units (CFU) per $d$. At the end of the pilot study all consumers confirmed that the fermented GM had a good taste and they consumed it with pleasure, but the GM consumers did not like it very much, because of the particular taste and smell.

\section{Origin of microbial strains and product development}

Combining the probiotic Lactobacillus strain with some other lactobacilli of different origin, we developed the fermented probiotic GM. All lactobacilli strains belonged to the culture collection of the Department of Microbiology, Tartu University. The lactobacilli strains selected for the present study had been isolated from the human GIT (Sepp et al. 1997; Mikelsaar et al. 2002). Three selected lactobacilli strains (L. fermentum ME-3, L. buchneri S-15, L. plantarum LB-4) fermented GM successfully and provided a yoghurt-like consistency and a satisfactory taste. L. fermentum ME-3 originated from a healthy 1 year-old Estonian child and was deposited in the Deutsche Sammlung von Mikroorganismen und Zellkulturen as 14241, L. buchneri S-15 originated from 1-2-year-old healthy Swedish infants and L. plantarum LB-4 originated from cheese whey.

L. fermentum ME-3 was included as a probiotic strain with high-grade antioxidative properties. We established initially that the other strains did not have principal antioxidativity (measured by using two different methods for total antioxidative activity (TAA)) (Kullisaar et al. 2002). Some obligatively heterofermentative lactobacilli species (L. buchneri, L. brevis) have shown potent enzymatic activity towards GM short-chain fatty acids (A Vafopoulou-Mastrojiannaki and E Litopoulou-Tzanteaki, unpublished results). L. buchneri strain S1-5 reduced the specific taste of GM. L. plantarum LB-4 was included as a strong producer of exopolysaccharides, which gives the fermented milk a cream-like consistency and recommended acidity.

Each LAB strain was incubated for $48 \mathrm{~h}$ in de Man, Rogosa and Sharpe medium (CM 361; Oxoid Ltd, Basingstoke, Hants., UK) at $37^{\circ} \mathrm{C}$ for $48 \mathrm{~h}$ in microaerobic conditions. The fresh GM was inoculated with a mixture of probiotic strains $(20 \mathrm{ml} / \mathrm{l})$ and incubated at $37^{\circ} \mathrm{C}$ for $24 \mathrm{~h}$. To get the proportional mixture every strain was incubated for $48 \mathrm{~h}$ in de Man, Rogosa and Sharpe medium (CM 361;
Oxoid Ltd) at $37^{\circ} \mathrm{C}$ for $48 \mathrm{~h}$ in microaerobic conditions. The product, ready to use, was cooled and stored at $4^{\circ} \mathrm{C}$.

\section{Specimen collection and microbial analyses of faeces}

The faecal samples were collected at the beginning (day 0) and at the end of the trial (day 21) and kept at $-80^{\circ} \mathrm{C}$ before analysis. Serial dilutions of the weighed faecal samples were prepared with phosphate buffer $(\mathrm{pH} 7 \cdot 2)$ and $0.05 \mathrm{ml}$ of each dilution was plated onto de Man, Rogosa and Sharpe agar medium (Mikelsaar et al. 1972). The plates were incubated at $37^{\circ} \mathrm{C}$ for $4 \mathrm{~d}$ microaerobically in a $10 \% \mathrm{CO}_{2}$ environment $\left(\mathrm{CO}_{2}\right.$ thermostat IG 150 ; Jouan, Saint-Herblain, France). Representative colonies were selected on the basis of colony morphology, cells microscopy and Gram staining.

The counts of lactobacilli were given as $\log \mathrm{CFU} / \mathrm{g}$ faeces. In addition, the relative amounts of the particular microbes were expressed as a proportion (\%) of the total count. The Lactobacillus spp. isolates were identified according to the absence of catalase activity, production of gas from glucose, growth temperature at $15^{\circ} \mathrm{C}$ and fermentation of sorbitol and tagatose (Lenzner et al. 1984; Mikelsaar et al. 2002). Vancomycin resistance differentiated Vancomycin-sensitive cocci, L. acidophilus group and L. salivarius from facultative and obligatively heterofermentative lactobacilli. Tests (Lenzner \& Lenzner, 1982) to verify hydrolysis of arginine and production of lysozyme were also carried out. L. fermentum was identified according to gas production, no growth at $15^{\circ} \mathrm{C}$, arginine hydrolysis and lysozyme activity.

\section{Experimental protocol}

Blood was sampled from the antecubital vein before and after consumption of GM or fermented GM. Blood (serum or plasma) was analysed for TAA, total antioxidant status (TAS), glutathione redox ratio (oxidized glutathione:reduced glutathione), oxidation resistance of blood lipoprotein fraction (LPF) (lag time of LDL + VLDL fraction), baseline value of diene conjugates of LPF, and the oxidized LDL level, and urine was analysed for 8-isoprostanes (8-epi-prostaglandin $\mathrm{F}_{2 \alpha}$ (EPI).

\section{Total antioxidative activity and status}

TAA of serum was assessed by using the linolenic acid test. This test evaluates the ability of sample to inhibit linolenic acid (L 2376; Sigma, St Louis, MO, USA) peroxidation (Pähkla et al. 1998). The standard of linolenic acid $(10 \mathrm{mg} / \mathrm{l}$ ethanol $(960 \mathrm{ml} / \mathrm{l}))$ was diluted in isotonic saline $(9 \mathrm{~g} \mathrm{NaCl} / 1 ; 8 \mathrm{ml}$ standard/l). SDS $(0.1 \mathrm{~g} / \mathrm{l})$ (lauryl sulphate L-5750; Sigma) was added to $0.4 \mathrm{ml}$ linolenic acid, diluted in isotonic saline $(9 \mathrm{~g} \mathrm{NaCl} / \mathrm{l})$ and the sample. The incubation was started by adding $100 \mathrm{~m} \mathrm{FeSO}_{4}$ (Final Fe concentration $0.2 \mathrm{~mm}$; F-7002, Sigma) and the mixture was incubated at $37^{\circ} \mathrm{C}$ for $60 \mathrm{~min}$. Then the reaction was interrupted by adding $0.035 \mathrm{ml}$ butylated hydroxytoluene (B1378; Sigma) and the mixture was treated with $0.5 \mathrm{ml}$ acetate buffer $(\mathrm{pH} 3.5)$, consisting of glacial acetic acid and sodium acetate trihydrate (A-6283 and S-8625 
respectively; Sigma), and heated with freshly prepared thiobarbituric acid solution $(10 \mathrm{ml} / \mathrm{l})(\mathrm{T}-5500$; Sigma) at $80^{\circ} \mathrm{C}$ for $40 \mathrm{~min}$. After cooling, the mixture was acidified by adding $0.5 \mathrm{ml}$ cold $5 \mathrm{M}-\mathrm{HCl}$, extracted with $1.7 \mathrm{ml}$ cold 1-butanol (BT-105; Sigma) and centrifuged at $3000 \mathrm{~g}$ for $10 \mathrm{~min}$ and the thiobarbituric acid reactivity ( $\mu \mathrm{M}$ malondialdehyde equivalents) of the butanol fraction was measured spectrophotometrically at $534 \mathrm{~nm}$. The TAA of sample was expressed as inhibition by the sample of linolenic acid standard peroxidation as follows: $\left(1-\left(\mathrm{A}_{534}\right.\right.$ (sample)/ $\mathrm{A}_{534}$ (linolenic acid as control) $) \times 100$, where $\mathrm{A}$ is absorbance. The higher value (\%) of TAA indicates a higher TAA of the sample. Peroxidation of linolenic acid standard in the isotonic saline $(9 \mathrm{~g} \mathrm{NaCl} / \mathrm{l}$, without serum) served as a control.

To measure TAS of serum, we used a commercially available kit (TAS; Randox Laboratories Ltd, Ardmore, UK). This method is based on the inhibition of the absorbance of the ferrylmyoglobin radicals of 2,2' -azinobisethylbenzothiazoline 6-sulfonate generated by activation of metmyoglobin peroxidase with $\mathrm{H}_{2} \mathrm{O}_{2}$. The suppression of the absorbance of $2,2^{\prime}$-azinobis-ethylbenzothiazoline 6-sulfonate radicals by sample depends on TAS of the sample under investigation (Rice-Evans \& Miller, 1994). The assay procedure was as follows. To $1 \mathrm{ml}$ chromogen (metmyoglobin) solution was added $0.02 \mathrm{ml}$ blood serum (blank was ultrapure water) and standard (6-hydroxy-2, 5,7,8-tetramethylchroman), mixed well and initial absorbance was read. Then $0.2 \mathrm{ml}$ substrate $\left(\mathrm{H}_{2} \mathrm{O}_{2}\right.$ in stabilized form) was added, mixed, incubated at $37^{\circ} \mathrm{C}$ and the absorbance at $600 \mathrm{~nm}$ was read after exactly $3 \mathrm{~min}$. The TAS values are expressed as Trolox units (mmol/l). Trolox is water soluble vitamin E $(2.5 \mathrm{~mm})$ it was prepared by dissolving $0 \cdot 15641 \mathrm{~g}$ Trolox in $250 \mathrm{ml}$ PBS.

\section{Reduced and oxidized glutathione and glutathione redox status}

Total glutathione and oxidized glutathione were measured by using the method described earlier (Griffith, 1980). The samples were deproteinated with metaphosphoric acid (100 ml/l) (M 5046; Sigma). An equal volume of metaphosphoric acid was added to the sample and mixed vigorously. The mixture was allowed to stand at room temperature for $5 \mathrm{~min}$ and centrifuged at $3000 \mathrm{~g}$ for $5 \mathrm{~min}$. The supernatant fraction was carefully collected and stored at $-20^{\circ} \mathrm{C}$ if the assay was not performed immediately. For measurement of the glutathione content, to $0.1 \mathrm{ml}$ sample was added $0.005 \mathrm{ml} 4 \mathrm{M}$-triethanolamine (TEAM reagent T1377; Sigma) in water and mixed immediately. Then the sample was divided into two portions. For assay of oxidized glutathione, reduced glutathione was derivatized by adding $0.1 \mathrm{ml} 2$-vinylpyridine (13,229-2; Sigma-Aldrich, Steinheim, Germany) in $1 \mathrm{~mm}-$ ethanol to a portion of the sample, mixing on a vortex mixer and keeping at room temperature for $1 \mathrm{~h}$. To determine the content of oxidized glutathione, $0 \cdot 1 \mathrm{ml}$ derivatized sample was added to $0.2 \mathrm{M}$-sodium phosphate buffer $(\mathrm{pH}$ 7.5) containing $0.01 \mathrm{M}$-EDTA, $0.5 \mathrm{U}$ glutathione reductase (G-4751; Sigma) and 0.3 mM-NADPH (N-7505; Sigma) was added and mixed immediately. The enzymatic reaction was initiated by addition of $0 \cdot 1 \mathrm{ml} 1 \mathrm{~mm}-5,5^{\prime}$-dithio-bis-2nitrobenzoic acid (D-8130; Sigma) in $0.2 \mathrm{M}$-sodium phosphate buffer ( $\mathrm{pH} \mathrm{7.5)}$ containing 0.01 M-EDTA (Griffith, 1980). The change in optical density was measured spectrophotometrically at $412 \mathrm{~nm}$ after $10 \mathrm{~min}$. The glutathione content was calculated on the basis of a standard curve generated with known concentration of glutathione. The amount of reduced glutathione was calculated as the difference between the total glutathione and oxidized glutathione (total glutathione - oxidized glutathione $=$ reduced glutathione). The glutathione content was expressed as $\mu \mathrm{g} / \mathrm{ml}$ sample or as glutathione redox ratio (oxidized glutathione:reduced glutathione).

\section{Isolation and oxidation of lipoprotein fraction}

Blood samples were collected by venepuncture into tubes containing EDTA and plasma was obtained by centrifugation at $1500 \mathrm{~g}$ for $15 \mathrm{~min}$. The LPF (non-HDL fraction) was precipitated from $2 \mathrm{ml}$ twice-diluted plasma by adding $0.2 \mathrm{ml}$ precipitation reagent (dextran sulfate $(20 \mathrm{~g} / \mathrm{l})-$ $\mathrm{Mg} \mathrm{Cl}_{2}$ (2 M, pH 7.0) (1:1, v/v)); vortexing for $1 \mathrm{~min}$ and centrifuging at $1500 \mathrm{~g}$ for $10 \mathrm{~min}$ (Zhang et al. 1994). In order to remove EDTA from the LPF, the pellet was suspended in $2 \mathrm{ml}$ PBS $(9 \mathrm{ml} / \mathrm{l})$ and reprecipitated by adding $0.1 \mathrm{ml}$ precipitation reagent, vortexed and centrifuged. The precipitated LPF was dissolved in $2 \mathrm{ml}$ PBS $(40 \mathrm{ml} / \mathrm{l})$ and this solution was used immediately. The protein content in LPF was assayed by using the method of Lowry et al. (1951). The protein concentration of EDTA-free LPF was adjusted to $2 \mathrm{mg}$ protein $/ \mathrm{ml}$. The resistance of LPF to $\mathrm{Cu}$-catalysed oxidation (lagphase of LPF) was estimated according to the method described earlier (Esterbauer et al. 1989; Zhang et al. 1994) with some modifications. Briefly, the oxidation was initiated by the addition of a freshly prepared aqueous solution of $\mathrm{CuSO}_{4} .5 \mathrm{H}_{2} \mathrm{O}$ (final concentration $45 \mu \mathrm{M}$ ) to the LPF $(2 \mathrm{mg}$ protein $/ \mathrm{ml})$ and the oxidation of this fraction was evaluated by continuously monitoring the formation of conjugated dienes at a maximum absorbance of $234 \mathrm{~nm}$ at different intervals of incubation at $37^{\circ} \mathrm{C}$. The kinetics of the diene formation (the increase of the absorbance $v$. time) can be divided into three phases: lag phase (during which the diene absorption increases only weakly); propagation phase (rapid increase of the diene absorption); decomposition phase. The resistance to oxidation is defined as the length of lag phase. The lag phase (lag time) was calculated from the interval between the intercept of the tangent of the slope of the curve with time-scale axis. LDL baseline of diene conjugation was evaluated as arbitrary units of absorbance of conjugated dienes at $234 \mathrm{~nm}$.

\section{Oxidized LDL level}

Oxidized LDL level was measured by using a Mercodia Oxidized LDL ELISA kit (catalogue no. 10-1143-01; Mercodia AB, Uppsala, Sweden). Mercodia Oxidized LDL ELISA is a solid-phase two-site enzyme immunoassay, based on direct sandwich technique in which two monoclonal antibodies are directed against separate antigenic determinants on the oxidized apolipoprotein 
B molecule. During the incubation and simple washing step that removes non-reactive plasma components, a peroxide-conjugated anti-apolipoprotein B antibody recognizes the oxidized LDL bound to the solid phase. After a second incubation and simple washing step that removes unbound enzyme-labelled antibody, the bound conjugate is detected by reaction with $3,3^{\prime}, 5,5^{\prime}$-tetramethylbenzidine. Adding acid stopped the reaction and the microtitration strips were read spectrophotometrically at $450 \mathrm{~nm}$.

\section{The content of 8-isoprostanes in urine}

This assay is a competitive ELISA for determining levels of 8-EPI in biological samples (BIOXYTECH 8-Isoprostane Assay, catalogue no. 21019; Cutter Circle, Portland, OR, USA). Briefly, 8-EPI in the samples or standards competes for binding (to the antibody coated on the plate) with 8-EPI conjugated to horseradish (Amoracia rusticana) peroxidase. The peroxidase activity results in colour development when the substrate is added. The intensity of the colour is proportional to the amount of 8-EPI-horseradish peroxidase bound and inversely proportional to the amount of 8-EPI in the samples or standards.

\section{Statistical analysis}

Calculations were performed using commercially available statistical software packages (Statistics for Windows, Stat Soft Inc.; Graph Pad PRISM, version 2.0; GraphPad Software Inc., San Diego, CA, USA) and software R, version 1.6.0 for Windows (The R Project, 2002). The values are given as means and standard deviations. Statistically significant differences inside the two groups were determined by using Student's $t$ test. In all analyses $P<0.05$ was considered statistically significant. The differences between GM and fermented GM groups (an effect of fermentation) were determined by using regression analysis.

The relative amounts of the probiotic strains colonizing the GIT of subjects in the study groups were expressed as a proportion of the total count (\%), using the Bioquant statistical program (Mändar et al. 1992), which gives output data for every micro-organism as an absolute count (log CFU/g) and their percentage in the total count with its normal values. Mann-Whitney rank sum tests and Fisher exact tests were used to compare the prevalence, counts and proportions of lactobacilli strains in faecal samples.

The Ethical Committee of Tartu University approved the study according to the Helsinki-II declaration. All subjects gave written consent before the experimental procedure and all had been carefully informed.

\section{Results}

The fresh GM used contained four different unidentified species of cocci (total counts $10^{9} \mathrm{CFU} / \mathrm{ml}$ ) and L. plantarum $\left(3 \times 10^{4} \mathrm{CFU} / \mathrm{ml}\right)$. After fermentation the increase in counts of lactic acid-producing microflora of the product was seen. The counts of lactococci and L. plantarum increased nearly 15 -fold (cocci $10^{10}$, L. plantarum $10^{6} \mathrm{CFU} / \mathrm{ml}$ ). The counts of probiotic
L. fermentum ME-3 reached $3 \times 10^{9} \mathrm{CFU} / \mathrm{ml}$ product, and the counts of the other starter cultures were somewhat lower (L. plantarum LB-4 reached $3 \times 10^{8}$ and L. buchneri $\mathrm{S}-15$ up to $4 \times 10^{8}$ ). The product, ready to use, was cooled and stored at $4^{\circ} \mathrm{C}$.

Prolonged consumption (21 d) of fermented probiotic GM altered the counts of lactobacilli after treatment with fermented GM (6.0 (SD 2.3) v. 7.6 (SD 0.9) CFU/g, $P=0.025)$. In addition, the prevalence and proportion of LAB species also changed in the study group compared with their microflora before the trial. L. fermentum appeared in all individuals ( $n$ 16) in the study group $(P<0.001)$, while in four subjects it was found before the trial. In the control group $L$. fermentum appeared only in one person. In addition, some new species, such as L. acidophilus and L. salivarius, were isolated from the GIT of the fermented GM consumers (Table 1). The proportional amount of L. fermentum and L. plantarum was significantly increased $P<0.01$ and $P<0.05$ respectively (Table 1). The indices of L. casei, L. brevis and Thermobacteria did not change in both groups.

\section{Total antioxidative activity and total antioxidant status tests}

Consumption of GM or fermented GM for $21 \mathrm{~d}$ enhanced TAA and TAS in both groups. There was an additional increase of TAA and TAS in the fermented GM group, but it was not statistically significant (Table 2).

\section{Reduced and oxidized glutathione and glutathione redox ratio}

The 3 weeks consumption of GM or fermented GM lowered the glutathione redox ratio (oxidized glutathione:reduced glutathione). This decrease was statistically significant $(P<0.008)$ in both groups. Fermented GM had no statistically significant additional effect (Table 2 ).

The lag time and baseline value of diene conjugates level of the lipoprotein fraction and level of oxidized $L D L$

Consumption of fermented GM for 3 weeks increased the lag time statistically significantly $(P<0.003)$; however, the additional effect of fermented GM remained statistically non-significant (Table 2). The baseline value of diene conjugates level of LPF (non-HDL fraction) was decreased only in the fermented GM group and the effect of fermentation was statistically significant $(P<0.003)$ (Table 2). The amount of oxidized LDL decreased only in the fermented GM group and this effect of fermentation was also statistically significant $(P<0 \cdot 05)$ (Table 2$)$.

The content of 8-isoprostanes (8-epi-prostaglandin $F_{2 \alpha}$ ) in urine

Only the consumption of fermented GM lowered the 8-EPI levels in urine $(P<0 \cdot 005)$. In the GM group the level of 8 -EPI increased, but it was not a statistically significant elevation (Table 2). 
Table 1. Changes in faecal microflora of the goats' milk and the fermented goats' milk groups during the $21 \mathrm{~d}$ trialf

\begin{tabular}{|c|c|c|c|c|c|}
\hline \multirow[b]{2}{*}{ Lactobacillus species } & & \multirow{2}{*}{$\begin{array}{l}\text { Colonized } \\
\text { subjects }(n)\end{array}$} & \multirow{2}{*}{$\begin{array}{l}\text { Total counts of lactobacilli } \\
\text { (median, CFU/g) }\end{array}$} & \multicolumn{2}{|c|}{$\begin{array}{l}\text { Relative amount of } \\
\text { lactobacilli species in } \\
\text { total count (\%) }\end{array}$} \\
\hline & & & & Range & Median \\
\hline \multicolumn{6}{|c|}{ Fermented goats' milk group ( $n$ 16) } \\
\hline \multirow[t]{2}{*}{ L. fermentum } & Before & 4 & $1 \times 10^{7}$ & $0.7-5.77$ & 0 \\
\hline & After & $16+† \dagger$ & $2 \times 10^{7}$ & $0.5-49.9$ & $6 \cdot 10^{\star \star \star}$ \\
\hline \multirow[t]{2}{*}{ L. plantarum } & Before & 5 & $1 \times 10^{6}$ & $0.005-28.5$ & 0 \\
\hline & After & $13 \dagger$ & $4 \times 10^{6}$ & $0.08-7.69$ & $1.96^{*}$ \\
\hline \multirow[t]{2}{*}{ L. buchneri } & Before & - & - & - & - \\
\hline & After & $2 \times 10^{7}$ & 1 & 8.5 & 0 \\
\hline \multirow[t]{2}{*}{ L. acidophilus } & Before & - & - & - & - \\
\hline & After & 3 & $1 \times 10^{6}$ & $0.5-2.31$ & $0^{\star * *}$ \\
\hline \multirow[t]{2}{*}{ L. salivarius } & Before & - & - & - & - \\
\hline & After & 1 & $1 \times 10^{8}$ & 3.85 & 0 \\
\hline \multirow[t]{2}{*}{ Thermobacterium spp. } & Before & 3 & $2 \times 10^{7}$ & $1 \cdot 39-17 \cdot 3$ & 0 \\
\hline & After & 2 & $5 \times 10^{7}$ & $0.017-3.82$ & 0 \\
\hline \multirow[t]{2}{*}{ L. casei } & Before & 8 & $6 \times 10^{5}$ & $0.06-39.0$ & 0.05 \\
\hline & After & 4 & $2 \times 10^{6}$ & $0.67-16.0$ & 0 \\
\hline \multirow{2}{*}{ L. brevis } & Before & 2 & $3 \times 10^{6}$ & $0.07-0.28$ & 0 \\
\hline & After & 3 & $3 \times 10^{6}$ & $0.08-0.45$ & 0 \\
\hline \multicolumn{6}{|l|}{ Goat milks' group ( $n 5$ ) } \\
\hline \multirow{2}{*}{ L. fermentum } & Before & - & - & - & - \\
\hline & After & 1 & $1 \times 10^{8}$ & 32.9 & 0 \\
\hline \multirow[t]{2}{*}{ L. plantarum } & Before & $1 \times 10^{6}$ & 2 & $0.026-2.74$ & 0.01 \\
\hline & After & - & - & - & - \\
\hline \multirow[t]{2}{*}{ L. buchneri } & Before & - & - & - & - \\
\hline & After & - & - & - & - \\
\hline \multirow[t]{2}{*}{ L. acidophilus } & Before & - & - & - & - \\
\hline & After & 1 & $8 \times 10^{3}$ & 2.44 & 0 \\
\hline \multirow[t]{2}{*}{ L. salivarius } & Before & - & - & - & - \\
\hline & After & - & - & - & - \\
\hline \multirow[t]{2}{*}{ Thermobacterium spp. } & Before & 1 & $5 \times 10^{7}$ & $21 \cdot 7$ & 0 \\
\hline & After & 1 & $1 \times 10^{6}$ & 30.49 & 0 \\
\hline \multirow[t]{2}{*}{ L. casei } & Before & 2 & $3 \times 10^{6}$ & $1 \cdot 37-50$ & 0.68 \\
\hline & After & 3 & $1 \times 10^{5}$ & $0.5-6.0$ & 0.58 \\
\hline \multirow[t]{2}{*}{ L. brevis } & Before & - & - & - & - \\
\hline & After & 1 & $2 \times 10^{6}$ & 0.66 & 0 \\
\hline
\end{tabular}

CFU, colony-forming units; - , Below the detection level ( $<10 \mathrm{CFU} / \mathrm{g}$ ).

Median values were significantly different from those before the treatment (Mann-Whitney rank sum test): ${ }^{\star} P<0.05,{ }^{\star \star \star} P<0.001$.

Values were significantly different from those before treatment (Fisher exact test): $\uparrow P<0.05, \dagger \dagger \dagger P<0.001$.

$\ddagger$ For details of subjects, treatments and procedures, see p. 450 .

\section{Discussion}

The intestinal bacterial flora have a close relationship with the well-being of the host. In particular, bacteria that produce harmful substances directly damage the GIT, and some of such substances are absorbed causing disorders in various organs, inducing atherosclerosis, hypertension, carcinogenesis, liver diseases, autoimmune diseases and depressed immunity. These observations imply that improving composition of intestinal microflora could have great impact on the health of man.

In a previous study we have reported that our L. fermentum strain (assigned ME-3) has substantial antioxidant activity (Kullisaar et al. 2002). Based on GM, we have developed a fermented GM product with antioxidative lactobacilli strain $L$. fermentum ME-3 and carried out a pilot study concerning the antioxidative and antiatherogenic effects of this fermented GM.

The first finding of our present study was that the fermented GM consumers showed substantial gastrointestinal persistence of $L$. fermentum ME-3. Thus, we propose that in fermented GM consumers L. fermentum ME-3 survived the passage through the GIT. This is supported by the fact that before the trial, only four of sixteen subjects were colonized with $L$. fermentum. After the trial all sixteen members of the probiotics fermented GM group were colonized with this species, and in much higher quantities than before (Table 1), according to the bacteriological methods used. Concerning the faecal Lactobacillus sp., large individual variations have been described (Mikelsaar et al. 1998). The smaller set of Lactobacillus sp. in GM drinkers could be explained by the rather small number of subjects. Gastrointestinal appearance of L. fermentum in one of the subjects in the GM group (Table 1) can be considered as insignificant and random because our pilot trial did not prescribe severely restrictive special diets. Thus, we propose that during fermented GM consumption a clear persistence of $L$. fermentum ME-3 takes place (the nucleic acid-based typing of the re-isolated strain might be performed in the future).

Persistence of L. fermentum ME-3 can make the interaction between the cells of the host and L. fermentum 
ME-3 or its metabolites possible. Our next findings show that such interaction has an anti-atherogenic response. Only the consumption of fermented GM lowered statistically significantly the conjugated diene level in plasma LPF $(P<0.003)$, diminished the level of oxidized LDL $(P<0.05)$ and suppressed production of 8-EPI $(P<0.008)$ (Fig. 1 and Table 2). It is known that abnormal modification of plasma lipoproteins ultimately results in severe oxidation of lipoproteins (oxidized LDL). The latter plays a crucial role in the pathogenesis of atherosclerosis, being highly atherogenic. It directly damages the endothelial cells, disturbs recruitment of monocytes, facilitates conversion of monocytes to macrophages and macrophages to foam cells and eventually to fatty streak (Roberts \& Cooper, 2001). As all observed effects of fermented GM on plasma lipoproteins have an anti-atherogenic character (decreased amount of oxidized LDL in the subjects' blood, lowered conjugated diene level of LPF and increased oxidation resistance of LPF), we can state that our fermented GM has the anti-atherogenic effect.

It is well known that antioxidants can increase oxidation resistance of serum lipoproteins (Nyyssönen et al. 1994; Terahara et al. 2000). Among commercial strains Lactobacillus GG has a preventive activity against the cholesterol-induced peroxidation damages in the plasma lipoproteins in rats (Broccali et al. 2000) and a GAUSIDO culture (Enterococcus faecium and Streptococcus thermophilus) decreased the baseline of LDL-cholesterol in human plasma (Agerholm-Larsen et al. 2000).

Anti-atherogenicity of our fermented GM may be expressed by interplay of different factors. It is known that some lactobacilli enable production of antioxidants in the human GIT (Lin \& Chang, 2000; Ljungh et al. 2002). Most LAB try to eliminate excess of oxygen radicals and $\mathrm{H}_{2} \mathrm{O}_{2}$ by superoxide dismutase or by glutathione (Archibald \& Fridovich, 1981; de Vos, 1996). Our strain L. fermentum ME-3 possessed a notable level of reduced glutathione (Kullisaar et al. 2002), whereas the presence of some other thiol compounds in ME-3, able to scavenge reactive oxygen species and to maintain the needed cellular redox status, cannot be excluded. As the intestinal environment is highly prone to development of remarkable oxidative stress, it is possible that the active interaction

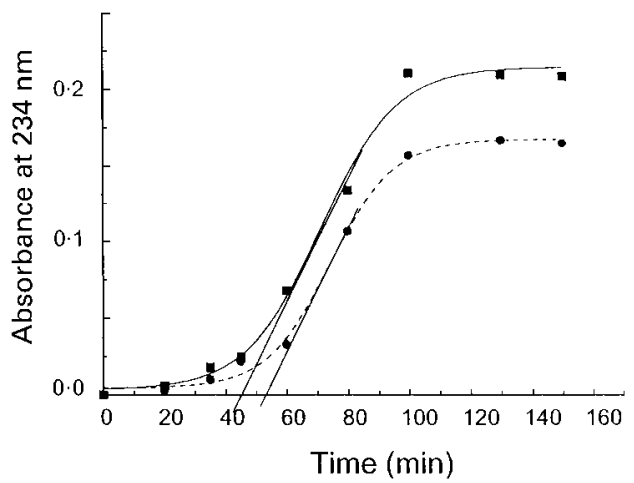

Fig. 1. The oxidation resistance (lag time) and maximal oxidation level of lipoprotein fraction (non-HDL fraction) before (ם) and after $(\bullet)$ consumption of fermented goats' milk (one typical experiment). For details of treatments and procedures, see p. 450. 
between our antioxidative probiotic and mucosal cells helps to maintain physiological redox status in the intestinal mucosa cells of the host. Like the gut-associated lymphoid tissue (Isolauri, 2001), the antioxidative network may also be affected by intestinal events in human subjects. Thus, putative secretion of anti-atherogenic compounds generated by probiotics might be expressed at the level of other body cells and lipoprotein particles. Our present results confirmed that the consumption of fermented GM substantially reduced the 8-EPI level in urine. Isoprostanes have been known to be good indices of body total oxidative stress-based atherogenicity and 8-EPI is probably the most valid direct measure of oxidative stress in vivo (Morrow et al. 1995; Patrono \& Fitzgerald, 1997; O'Brien et al. 2000).

Statistically significant elevation of TAA and decrease in isoprostanes and redox ratio confirms the improvement of both systemic and cellular antioxidativity of plasma. Some effects seem to be partially specific for GM, as both fermented GM and GM elevated the values of TAA and TAS and decreased the redox ratio. However, the elevation of these indices was expressed more in the fermented GM group and these variables refer to improved antioxidative status of subjects. GM contains casein (specially type $S_{1}$ ), short-chain fatty acids (greater proportion of capric, caprylic and caproic acids), several kinds of minerals (especially $\mathrm{Ca}$, $\mathrm{P}, \mathrm{Co}$ and Mo) and vitamins (especially inositol, vitamin A and niacin) (E Alichanidis and A Polychoniadou, unpublished results), biomolecules, which can be incorporated into human plasma and contribute to plasma antioxidative capacity (Nakagawa et al. 2000), and/or bioactive antimicrobial peptides (Epland \& Vogel, 1999; Hancock \& Diamond, 2000), which may have also some antioxidative properties. Although it is very difficult to compare the action of LAB with the other antioxidants, having different characteristics, different intestinal absorption and different metabolism (Terahara et al. 2000), our present results show that $L$. fermentum ME-3 may have an effect as a promising anti-atherogenic probiotic. Certainly, systemic investigations are now needed to establish molecular aspects and mechanisms (including anti-atherogenic) underlying the positive effect of our probiotic.

In summary, the present pilot study has confirmed that our antioxidative probiotic L. fermentum ME-3 is able to survive in the GIT and exhibits antioxidative and anti-atherogenic effects in human subjects.

\section{Acknowledgements}

The authors would like to thank Mrs Mai Laanes for excellent technical assistance. Funding no. 0411 and 0418 from Estonia Ministry of Education supported this work.

\section{References}

Agerholm-Larsen L, Raben A, Haulrik N, Hansen AS, Manders M \& Astrup A (2000) Effect of 8 weeks intake of probiotic milk products on risk factors for cardiovascular diseases. Eur J Clin Nutr 54, 288-297.
Archibald FS \& Fridovich I (1981) Manganese superoxide dismutase and oxygen tolerance in some lactic acid bacteria. J Bacteriol 146, 828-936.

Broccali G, Berti M, Pistolesi E \& Gestaro B (2000) Study of the effect of Lactobacillus $G G$ supplementation in combination with and without arginine aspartate lipoproteins and liver peroxidation in cholesterol-fed rats. Int J Food Sci Nutr 51, $475-482$.

Demple B, Hidalgo E \& Ding H (1999) Transcriptional regulation via redox-sensitive iron-sulphur centers in an oxidative stress response. Biochem Soc Symp 64, 119-128.

deRoos NM \& Katan MB (2000) Effects of probiotic bacteria on diarrhea, lipid metabolism and carcinogenesis: a review of papers published between 1988 and 1998. Am J Clin Nutr 71, 405-411.

de Vos WM (1996) Metabolic engineering of sugar catabolism in lactic acid bacteria. Antonie Van Leeuwenhoek 70, 223-224.

De Zwart LL, Meerman JHN, Commandeur JN \& Vermeulen NPE (1999) Biomarkers of free radical damage applications in experimental animals and in humans. Free Radic Biol Med 26, 202-226.

Epand RM \& Vogel HJ (1999) Diversity of antimicrobial peptides and their mechanisms of action. Biochim Biophys Acta 1462, $11-28$.

Esterbauer F, Striegl G, Puhl H \& Rothenedr M (1989) Continuous monitoring of in vitro oxidation of human low density lipoprotein. Free Radic Res Commun 6, 67-75.

Falk PG, Hooper EH, Midtvedt T \& Gordon JL (1998) Creating and maintaining the gastrointestinal ecosystem: what we know and need to know from gnotobiology. Microbiol Mol Biol Rev 62, 1157-1170.

Griffith OW (1980) Determination of glutathione and glutathione disulfide using glutathione reductase and 2-vinylpyridine. Anal Biochem 106, 207-212.

Hancock REW \& Diamond G (2000) The role of cationic antimicrobial peptides in innate host defence. Trends in Microbio 8, 402-410.

Isolauri E (2001) Probiotics in human disease. Am J Clin Nutr 73, $1142 S-1146 S$.

Isolauri E, Arvola T, Sütas E, Moilanen E \& Salminen S (2000) Probiotics in the management of atopic eczema. Clin Exp Allergy 30, 1604-1610.

Kailasapathy K \& Chin J (2000) Survival and therapeutic potential of probiotic organisms with reference to Lactobacillus acidaphilus and Bifidobacterium spp. Immunol Cell Biol 78, 80-88.

Kaizu H, Sasaki M, Nakajima H \& Suzuki Y (1993) Effect of antioxidative lactic acid bacteria on rats fed a diet deficient in vitamin E. J Dairy Sci 46, 2493-2499.

Kullisaar T, Zilmer M, Mikelsaar M, et al. (2002) Two antioxidative lactobacilli strains as promising probiotics. Int $J$ Food Microbiol 72, 215-224.

Lenzner AA, Lenzner ChP, Mikelsaar M, et al. (1984) Die quantitative zusammensetzung der lactoflora des verdauungstrakts vor und nach kosmischen flügen unterschiedlicher dauer (The quantitative composition of the gut lactoflora before and after cosmic flights of different duration). Nahrung 28, 607-613.

Lenzner HP \& Lenzner AA (1982) Lysozyme activity and susceptibility of Lactobacilli to lysozyme of human microflora lactobacilli. In Mikrobielle Umwelt und anti-mikrobielle Massnahmen (Microbial Environment and Antimicrobial Activity), pp. 73-81 [H Bernhardt and M Knoke, editors]. Leipzig: M Johann Ambrosius Barth Verlag.

Lin MY \& Chang FY (2000) Antioxidative effect of intestinal bacteria Bifidobacterium longum ATCC 15708 and Lactobacillus acidophilus ATCC 4356. Dig Dis Sci 45, 1617-1622. 
Lin MY \& Yen CL (1999) Antioxidative ability of lactic acid bacteria. J Agric Food Chem 47, 1460-1466.

Ljungh A, Lan J \& Yanagisawa N (2002) Isolation, selection and characteristics of Lactobacillus paracasei subsp. paracasei F19. Microb Ecol Health Dis Suppl. 3, 4-6.

Lowry OH, Rosenbrough NJ, Farr AL \& Randall RJ (1951) Protein measurement with the Folin phenol reagent. J Biol Chem 193, 265-275.

McFarland LV (2000) Beneficial microbes: health or hazard? Eur J Gastroenterol Hepatol 12, 1069-1071.

Mändar R, Mändar H \& Mikelsaar M (1992) Bioquant - a program for evaluation of faecal microbiocenosis In 1. Baltic Congress of Laboratory Medicine. Clin Chem Lookout 56.

Mikelsaar M, Annuk H, Shchepetova J, Mändar R, Sepp E \& Björksten B (2002) Intestinal lactobacilli of Estonian and Swedish children. Microb Ecol Health Dis 14, 75-80.

Mikelsaar M, Lenzner A \& Goljanova LA (1972) Methods for the estimation of the quantitative composition of faecal microflora. Lab Delo 1, 41-45.

Mikelsaar M, Mändar R \& Sepp E (1998) Lactic acid microflora in the human microbial ecosystem and its development. In Lactic Acid Bacteria, Microbiology and Functional Aspects, pp. 279-343 [S Salminen and A von Wright, editors]. New York: M. Dekker, Inc.

Morrow JD, Frei B, Longmire AW, et al. (1995) Increase in circulating products of lipid peroxidation (F2-isoprostanes) in smokers. New Eng J Med 332, 1198-1203.

Nakagawa K, Ninomiya M, Okubo T, et al. (2000) In vitro and vivo antioxidant properties of gliclazide. $J$ Diabetes Complications 14, 201-206.

Nyyssönen K, Porkkola E, Salonen R, Korpela H \& Salonen JT (1994) Increase in oxidation resistance of atherogenic serum lipoproteins following antioxidant supplementation: a randomized double-blind placebo-controlled clinical trial. Eur J Clin Nutr 48, 633-642.

O'Brien RC, Luo M, Balazs \& Mecuri J (2000) In vitro and vivo antioxidant properties of gliclazide. J Diabetes Complications 14, 201-206.

Oxman T, Shapira M, Diver A, Klein R, Avazov N \& Rabinowitz B (2000) A new method of long-term preventive cardioprotaction using Lactobacillus. Am J Physiol 278, H1717-H1724.

Patrono C \& Fitzgerald GA (1997) Isoprostanes: potential markers of oxidant stress in atherothrombotic disease. Arterioscler Thromb Vasc Biol 17, 2309-2315.

Pähkla R, Zilmer M, Kullisaar T \& Rägo L (1998) Comparison of the antioxidant activity of melatonin and pinolin in vitro. J Pineal Res 24, 96-101.

Rice-Evans C \& Miller NJ (1994) Total antioxidant status in plasma and body fluids. Methods Enzymol 234, 279-293.

Roberts JM \& Cooper DW (2001) Pathogenesis and genetics of pre-eclampsia. Lancet 357, 53-55.

Sepp E, Julge K, Vasar M, Naaber P, Björgsten B \& Mikelsaar M (1997) Intestinal microflora of Estonian and Swedish children. Acta Pediatr 86, 956-961.

The R Project (2002) The R project for statistical computing. http://www.r-project.org.

Terahara M, Nishide S \& Kaneko T (2000) Preventive effect of Lactobacillus delbrueckii subsp. bulgaricus on the oxidation of LDL. Biosci Biotechnol Biochem 64, 1868-1873.

Zhang A, Vertommen G, Van Gaal L \& De Leeun I (1994) A rapid and simple method for measuring the susceptibility of low-density-lipoprotein and very-low-density-lipoprotein to copper catalyzed oxidation. Clin Chim Acta 227, $159-173$. 